\title{
BMJ Open Social, biological, behavioural and psychological factors related to physical activity during early pregnancy in the Screening for Pregnancy Endpoints (Cork, Ireland) cohort study
}

To cite: Flannery C, Dahly D, Byrne M, et al. Social, biological, behavioural and psychological factors related to physical activity during early pregnancy in the Screening for Pregnancy Endpoints (Cork, Ireland) cohort study. BMJ Open 2019;9:e025003. doi:10.1136/ bmjopen-2018-025003

- Prepublication history and additional material for this paper are available online. To view these files, please visit the journal online (http://dx.doi org/10.1136/bmjopen-2018025003).

Received 25 June 2018 Revised 28 March 2019 Accepted 29 March 2019

Check for updates

(C) Author(s) (or their employer(s)) 2019. Re-use permitted under CC BY-NC. No commercial re-use. See rights and permissions. Published by BMJ.

For numbered affiliations see end of article.

Correspondence to Dr Caragh Flannery; cflannery@ucc.ie

\section{ABSTRACT}

Objective The aim of this study was to identify the social, biological, behavioural and psychological factors related to physical activity (PA) in early pregnancy.

Design This is a secondary analysis of data from a prospective cohort study.

Setting The study was conducted in Cork, Ireland.

Participants Nulliparous women with singleton

pregnancies were recruited and then interviewed at $15 \pm 1$ weeks' gestation.

Primary and secondary outcomes The biopsychosocial model identified factors including social (age), biological (body mass index), behavioural (diet) and psychological (anxiety) at $15 \pm 1$ weeks' gestation. PA subgroups were identified based on a latent class analysis of their responses to a set of questions about the amount and intensity of activity they were engaging in during the pregnancy. Associations were estimated with multivariable multinomial logistic regression models.

Results From a total of 2579, 1774 (69\%) women were recruited; ages ranged from 17 to 45 years. Based on a combination of model fit, theoretical interpretability and classification quality, the latent class analyses identified three PA subgroups: Iow PA ( $\mathrm{n}=393)$, moderate PA ( $\mathrm{n}=960)$ and high PA ( $\mathrm{n}=413)$. The fully adjusted model suggests non-smokers, and consumers of fruit and vegetables were more likely to be in the high PA subgroup (vs low). Women with more than 12 years of schooling and a higher socioeconomic status were more likely to be in the moderate PA subgroup (vs low).

Conclusion The findings highlight potential links between PA, a low education level and a low socioeconomic background. These factors should be considered for future interventions to improve low PA levels during pregnancy. Trial registration number ACTRN 12607000551493.

\section{INTRODUCTION}

Physical activity (PA) is defined as 'any bodily movement produced by skeletal muscles that requires energy expenditure' including leisure time PA, walking, household chores, games, sports or planned exercise, in the

\section{Strengths and limitations of this study}

- Multivariable multinomial logistic regression models were used to estimate the associations between physical activity (PA) and social, biological, behaviour and psychological factors in pregnancy within an Irish context.

- Maternal lifestyle factors were based on self-report and therefore subject to error.

- Latent class analysis was used to identify mutually exclusive subgroups in order to create a PA outcome measure that best describes the observed set of responses.

context of daily, family and community activities. ${ }^{1}$ National and international guidelines for pregnancy recommend $30 \mathrm{~min}$ or more of daily moderate PA, or $150 \mathrm{~min}$ of moderate PA spread throughout the week. ${ }^{2-6}$ Regular PA during pregnancy is beneficial for both mother and fetus as it helps to prevent complications, limit weight gain and decrease the risk of gestational diabetes. ${ }^{7}$ Despite these significant health benefits, PA is lower among pregnant women. ${ }^{89}$ Studies using self-report measures of PA in the UK and USA estimate that only $3 \%-15 \%$ of pregnant women meet current guidelines compared with $24 \%-26 \%$ of non-pregnant women. ${ }^{10} 11$ In Ireland, only one-fifth of pregnant women meet PA guidelines, and over $10 \%$ of pregnant women report no PA. ${ }^{9}$

Consequently, there is a need for effective strategies to increase activity during pregnancy. Recognising and understanding the correlates of PA, as well as explaining how these correlates may influence subsequent behaviour, are fundamental to intervention development and implementation.

Previous observational studies have found that demographic factors such as age, income 
and education are important correlates of participation in PA during pregnancy. ${ }^{12-14}$ Furthermore, factors such as body mass index (BMI) has been associated with both increased and decreased levels of exercise during pregnancy compared with prepregnancy levels. ${ }^{12}$ Of women who engaged in a regular exercise regime, those most likely to quit by the third trimester were women who had a high BMI and those who had gained more weight during pregnancy. ${ }^{12}$ Social factors such as unemployment have been shown to influence PA levels ${ }^{15} 16$ with higher education, a higher income and not having children being predictors of high exercise participation. ${ }^{14}$ These studies have used various PA measures such as recreational activity, occupation or household activity as opposed to total PA. Therefore, a further understanding of PA level is essential in order to increase activity during pregnancy.

Using data from a prospective Irish cohort, this study aimed to identify the different social, biological, behavioural and psychological factors that are linked with PA levels during pregnancy.

\section{METHODS}

\section{Study design and population}

This is a secondary analysis of the Irish data from the prospective cohort study Screening for Pregnancy Endpoints (SCOPE). SCOPE is multicentre cohort study (Cork, Auckland, Adelaide, London, Leeds and Manchester) with the main aim of developing screening tests to predict pre-eclampsia, small for gestational age infants and spontaneous preterm birth as previously described. ${ }^{17-19}$ In brief, healthy nulliparous women with singleton pregnancies were recruited and then interviewed at $15 \pm 1$ weeks' gestation from Cork University Maternity Hospital, Ireland $(n=1774)$ between March 2008 and February 2011 with the last baby born in August 2011. At $15 \pm 1$ and $20 \pm$ weeks' gestation, comprehensive data were collected on social factors including age, marital status, ethnicity, accommodation, socioeconomic Index (SEI); behavioural and psychological factors before conception and during pregnancy. Women were followed prospectively and research midwives collected data on pregnancy outcomes and measurements of the baby. For the purpose of this study, only data collected at $15 \pm 1$ are analysed. The Strengthening the Reporting of Observational Studies in Epidemiology checklist for cohort studies was used to inform reporting of the findings (online supplementary file 1).

\section{Patient and public involvement}

This is a secondary analysis using data from the SCOPE study. Pregnant women were not directly involved in the design or administration of this analysis.

\section{Outcome measure}

In three separate questions, participants were asked how often they engaged in vigorous exercise (exercise which made you breathe harder or pant), moderate exercise (exercise which did not make you breathe harder or pant) and recreational walking (walking for recreation or exercise). Responses to each of the three questions were self-reported and coded as never, once a week, two to three times a week, four to six times a week, daily and more than twice daily. Latent class analysis was used to identify mutually exclusive subgroups in the sample of participants based on these three categorical survey items. ${ }^{20}$ The central challenge to any latent class model is to select the appropriate number of classes (or subgroups) that best describe the observed set of responses. Because the number of latent class must be set by the user, we estimated a series of models where the number of latent classes ranged from one to six. The authors then met to discuss the results and a final number of latent classes were selected based on model fit statistics (using Akaike information criterion and Bayesian information criterion), parsimony, theoretical interpretability and classification quality. Once the final model was chosen, participants were assigned to their most likely class (ie, their modal assignment). Latent class models were estimated using MPlus V.8.0.

\section{Covariates}

Social measures

Characteristics included maternal age (years or age category; <25years, 25-29 years, 30-34 years, $\geq 35$ years); ethnicity (Caucasian vs non-Caucasian); relationship status (single, married/partner); employment status (working us not working); accommodation (own home or other); education $(\leq 12$ years of schooling $v s>12$ years of schooling) and type of maternity care services (public vs private) used. SEI was based on an occupation-based measure of socioeconomic status 'New Zealand SEI' ( $<24 \mathrm{vs} \geq 24)$, with higher values reflecting greater social status. ${ }^{21}$

\section{Biological measures}

Gravidity ( 1 vs $>1$ ) was collected at $15 \pm 1$ weeks' gestation. Body mass index (BMI) was calculated from pregnancy weight $(\mathrm{kg})$ divided by measured height squared $\left(\mathrm{m}^{2}\right)$ from the first SCOPE visit at $15 \pm 1$ weeks' gestation. BMI was categorised based on the WHO guidelines as underweight $\left(<18.5 \mathrm{~kg} / \mathrm{m}^{2}\right)$, normal weight $\left(18.5-24.9 \mathrm{~kg} / \mathrm{m}^{2}\right)$, overweight $\left(\geq 25-29.9 \mathrm{~kg} / \mathrm{m}^{2}\right)$ and obese $\left(\geq 30 \mathrm{~kg} / \mathrm{m}^{2}\right) .{ }^{22}$

\section{Psychological and behavioural measures}

Based on participant reported consumption, alcohol measured as drinks per week at $15 \pm 1$ weeks' gestation (no drinks, 1-2 drinks, 3-7 drinks, 8-14 drinks, >14 drinks) was categorised as (drinkers $(\geq 1$ drink) vs non-drinkers (no drink)); and smoking per day at $15 \pm 1$ weeks' gestation (no smoking, 1-5 cigarettes, 6-10 cigarettes, $>10$ cigarettes) was categorised as (smokers ( $\geq 1$ cigarettes) vs non-smokers (no smoking)). Women were asked about prepregnancy folic acid supplementation (no, yes), and their responses (dose) were dichotomised as those meeting the recommended $400 \mu \mathrm{g}$ versus those who did not (yes vs no). The questionnaire administered at $15 \pm 1$ weeks' gestation 
- Smoking

- Alcohol

- Folate

- Fruit \& veg

- Fish

- Anxiety (STAl)

- Stress (PSS)

- Depression (EPDS)

- Limiting response

- All or nothing response

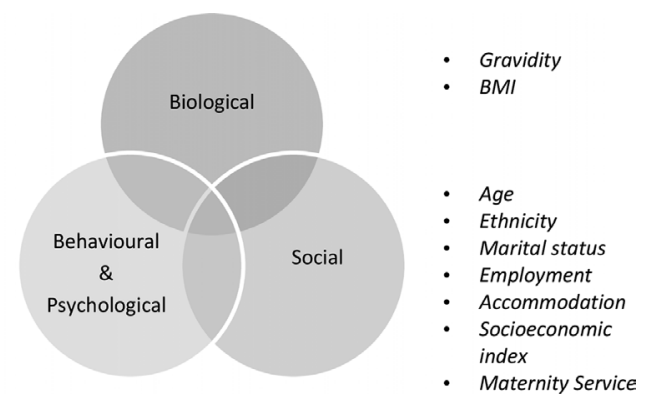

Figure 1 Biopsychosocial model for physical activity using data from the Irish cohort of Screening for Pregnancy Endpoints. BMI, body mass index; EPDS, Edinburgh Postnatal Depression Scale; PSS, Perceived Stress Scale; STAI, State-Trait Anxiety Index.

asked women to report the frequency with which they consumed fruit, vegetables and fish in the first 15 weeks of pregnancy. These responses were used to determine whether they were meeting the recommended five servings of fruit and vegetables per day (yes vs no), and at least one serving of oily fish per week (yes vs no).

Maternal anxiety was assessed using the short form of the State-Trait Anxiety Index, ${ }^{23}$ how much stress the woman experienced was measured using the Perceived Stress Scale ${ }^{24}$ and depressive symptoms were assessed using the Edinburgh Postnatal Depression Scale. ${ }^{25}$ Pregnancy-related behaviour was measured using the behavioural response to pregnancy scale: 'all or nothing' response describes an individual who pushes oneself to keep going until he/she find it physically impossible; 'limiting' response describes an individual who avoids daily activities. ${ }^{26}$ See online supplementary file 2 for their interpretations. ${ }^{27}$

\section{Statistical analysis}

Secondary analysis was performed using the Irish data from SCOPE in Stata V.13. The biopsychosocial model was used to identify factors that are associated with PA in early pregnancy. This model recognises the influences of the biological, psychological and social dimensions of a person's life (figure 1). ${ }^{28}$ Associations between participant characteristics and the PA subgroups identified in the latent class analysis were explored using $\chi^{2}$ test for categorical and analysis of variance (ANOVA) for continuous variables. Unadjusted multinomial logistic regression was conducted to examine the association between covariates and PA level. See online supplementary file 3 for the unadjusted associations. Multivariable multinomial logistic regression was conducted using a hierarchical approach ${ }^{29}$ whereby model 1 included the social factors, model 2 added the biological factors and model 3 was further adjusted for the behavioural and psychological factors. All variables are included in the adjusted model. Estimated coefficients are reported as relative risk ratios (RRRs) with $95 \%$ CI using those who reported low PA as the reference category. This is because the exponentiated coefficient in multinomial logistic regression is the ratio of two relative risks (RRR) and should not be interpreted as an OR.

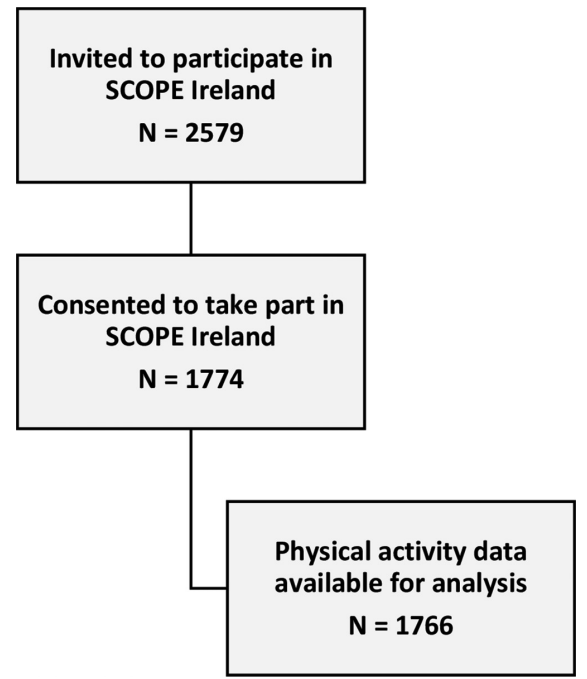

Figure 2 Flow diagram for Screening for Pregnancy Endpoints (SCOPE) Ireland.

\section{RESULTS}

\section{Sample characteristics}

A total of 2579 nulliparous women were invited to participate in the SCOPE Irish study, 1774 (69\%) consented to take part (figure 2). Ages ranged from 17 to 45 (mean age 30, SD 4.5). The SCOPE Ireland women were predominantly Caucasian $(n=1733,98 \%)$, married $(n=1584$, $89 \%)$, with $>12$ years of schooling $(n=1207,68 \%)$ and higher socioeconomic status $(n=1469,83 \%)$. The estimated proportions of women in each BMI category were normal $(n=1058,60 \%)$, overweight $(n=495,28 \%)$ and obese $(n=221,12 \%)$.

\section{PA levels}

PA data were available for 1766 women. Based on a combination of model fit, parsimony, theoretical interpretability and classification quality, the authors agreed that a three-class model was the most appropriate one (see online supplementary file 4). The three PA subgroups thus identified were characterised as follows: low levels of PA $(\mathrm{n}=393)$, moderate levels of PA $(n=960)$ and high levels of PA $(n=413)$. Based on $\chi^{2}$ test and ANOVA, PA subgroups were crudely associated with most of the variables considered (table 1 ).

\section{Multivariable logistic regression findings}

In the unadjusted multinomial logistic regression, the majority of social and behavioural factors where linked to either the moderate or high PA subgroups or both (see online Supplementary file 3). Therefore, all variables were included in the final model. Table 2 presents the findings of the multivariable logistic regression analyses with low $\mathrm{PA}$ as the reference category.

\section{Social, biological, behavioural and psychological}

In model 1, social factors such as employment, accommodation and type of maternity service were not statistically significant for moderate PA (vs low) or high PA (vs low). Furthermore, in model 2, biological factors BMI and 
Table 1 Social, biological, behavioural and psychological indicators by physical activity subgroup

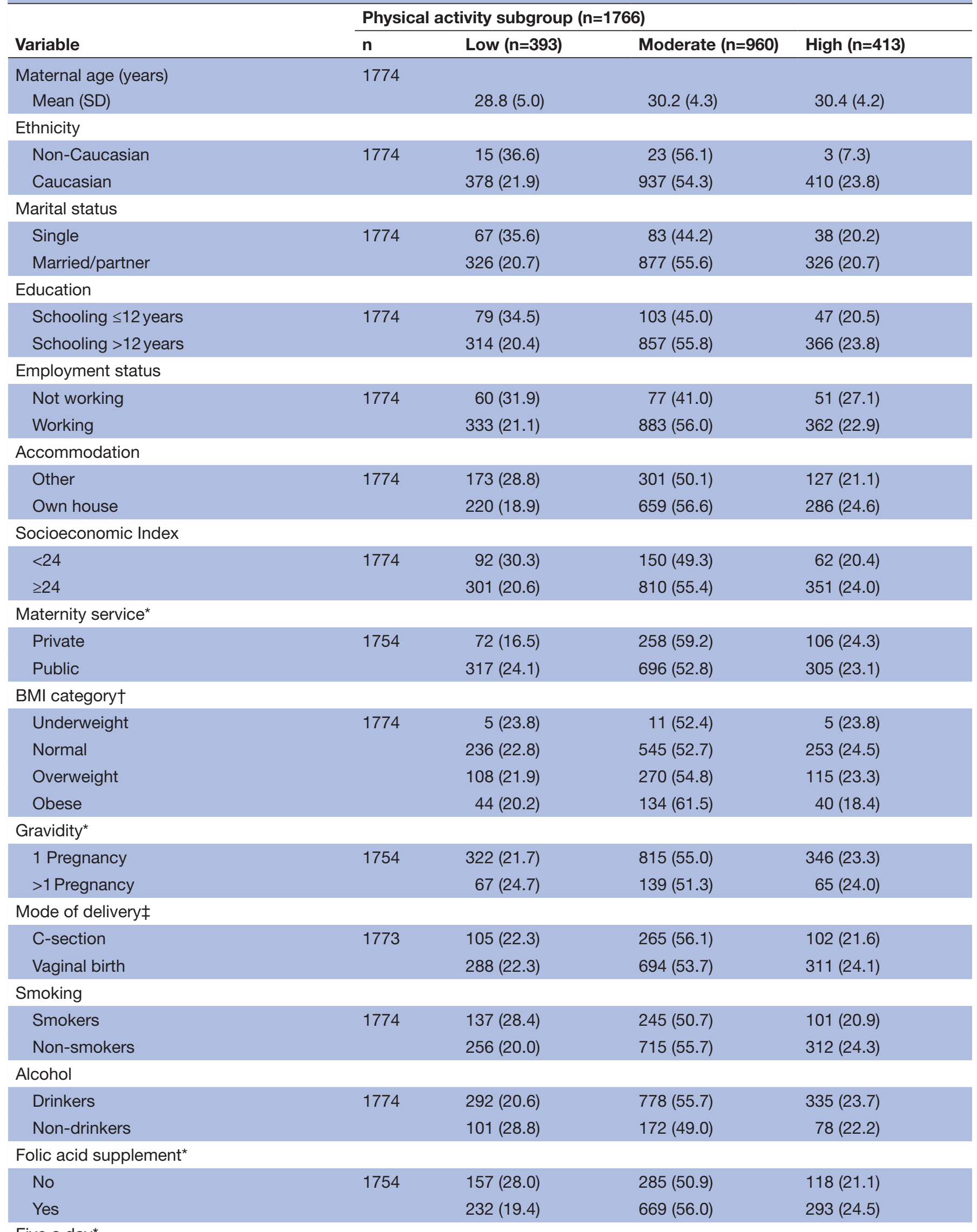

Five a day* 
Table 1 Continued

\begin{tabular}{llccc}
\hline \multirow{2}{*}{ Variable } & \multicolumn{4}{l}{ Physical activity subgroup $\mathbf{( n = 1 7 6 6 )}$} \\
\cline { 2 - 5 } & $\mathbf{n}$ & Low $\mathbf{( n = 3 9 3 )}$ & Moderate $(\mathbf{n}=\mathbf{9 6 0})$ & High $(\mathbf{n}=\mathbf{4 1 3})$ \\
\hline No & 1754 & $353(23.4)$ & $822(54.5)$ & $333(22.1)$ \\
Yes & & $36(14.6)$ & $132(53.7)$ & $78(31.7)$ \\
Fish* & & & & \\
$\quad$ No & 1754 & $291(24.2)$ & $647(53.7)$ & $267(22.2)$ \\
Yes & & $98(17.9)$ & $307(55.9)$ & $144(26.2)$ \\
Anxiety index & 1774 & $33(27-43)$ & $33(27-40)$ & $30(23-40)$ \\
Perceived Stress Scale & 1774 & $14(9-19)$ & $13(9-18)$ & $13(8-17)$ \\
Depression Scale & 1774 & $6(3-10)$ & $6(3-19)$ & $5(2-9)$ \\
Limiting response & 1774 & $9(5-12)$ & $8(6-10)$ & $6(3-9)$ \\
All or nothing response & 1774 & $7(4-11)$ & $8(5-11)$ & $8(5-11)$ \\
\hline
\end{tabular}

Data are means (SD) number (\%) and median (IQR). Kruskal-Wallis $\mathrm{H}$ or the $\chi^{2}$ test.

${ }^{*}$ Missing values.

†Body mass index (BMI) category was defined based on the WHO guidelines as underweight $\left(<18.5 \mathrm{~kg} / \mathrm{m}^{2}\right)$, normal weight $\left(18.5-24.9 \mathrm{~kg} / \mathrm{m}^{2}\right)$, overweight $\left(\geq 25-29.9 \mathrm{~kg} / \mathrm{m}^{2}\right)$ and obese $\left(\geq 30 \mathrm{~kg} / \mathrm{m}^{2}\right)$.

$\ddagger$ Recoded at birth.

gravidity were not statistically significant for moderate PA (vs low) or high PA (vs low).

Results from the fully adjusted model (table 2, model 3 ) suggest that social factors such as women aged 30-34 years (RRR 2.27 (95\% CI 1.23 to 4.22)) were associated with high PA (vs low), with non-Caucasians being less likely to be in the high PA subgroup (vs low) (RRR 0.23 (95\% CI 0.06 to 0.86$)$ ). Similarly, having $>12$ years of schooling (RRR 1.55 (95\% CI 1.06 to 2.26)) and a higher socioeconomic status $(\geq 24)$ (RRR 1.46 (95\% CI 1.05 to 2.05)) remained associated with moderate PA (vs low). Of the biological factors, the relative risk for obese women (BMI $>30 \mathrm{~kg} / \mathrm{m}^{2}$ ) would be expected to increase (RRR 1.49 (95\% CI 1.00 to 2.22)) for moderate PA relative to normal (BMI $<24 \mathrm{~kg} / \mathrm{m}^{2}$ ) (vs the low).

Accounting for social and biological factors, women who consumed five portions of fruit and vegetables a day (RRR 1.90 (95\% CI 1.22 to 2.96)) and oily fish (RRR 1.47 (95\% CI 1.07 to 2.03)) were more likely to be in the high PA subgroup (vs low) relative to those who did not consume fruit and vegetables or oily fish. Non-smokers were 1.45 times more likely to be in the high PA subgroup (vs the low) relative to those who reported smoking (RRR 1.45 (95\% CI 1.02 to 2.07)). For women who did not consume alcohol relative to those who drank, the relative risk for moderate PA group (vs the low) would be expected to decrease by a factor of 0.62 (RRR $0.62(95 \%$ CI 0.45 to 0.84$)$ ).

For psychological factors, the relative risk for moderate PA group (vs the low), for those who reported avoiding exercise as a response to pregnancy would be expected to increase by a factor of 1.03 (RRR 1.03 (95\% CI:1.00 to 1.01)) and the relative risk for high PA group (vs the low) would be expected to decrease by a factor of 0.85 (RRR 0.85 (95\% CI 0.81 to 0.88$)$ ) (vs the low). In addition, those who reported pushing oneself as a response to pregnancy were 1.04 times more likely to be in the high PA subgroup (RRR 1.04 (95\% CI 1.01 to 1.08)) (vs the low).

\section{DISCUSSION}

Women aged 30-34 years had increased probability of being in the high PA subgroup (vs the low) relative to women $<25$ years of age. Women with a higher educational level, in a higher social class and in the obese BMI category $(>30 \mathrm{~kg} /$ $\mathrm{m}^{2}$ ) had increased probability of being in the moderate PA subgroup (vs the low). Non-smokers were more likely to be in the high PA relative to smokers and women who consumed the recommended five servings of fruit and vegetables per day and at least one serving of oily fish per week were more likely to be in the high PA subgroup.

Women aged 30-34 years had increased probability of being in the high PA subgroup (vs the low). This is noteworthy given that other studies have reported higher levels of PA among younger age groups. ${ }^{13}$ Consistent with previous studies on PA, pregnant women with a higher educational level and in a higher social class were more likely to engage in moderate levels of PA. ${ }^{13} 3031$ Similar to other studies, factors associated with exercise during pregnancy include income level, no other children at home, white ethnicity and activity prior to pregnancy. ${ }^{14}$ Women with a high education may have access to more information, may be aware of the recommended guidelines and have more time for PA during pregnancy ${ }^{3032}$ From a public health perspective, a key concern is social inequalities in PA, as PA participation varies by socioeconomic status, favouring those in a higher social class. ${ }^{33}$ Women with a low education level and those of a lower socioeconomic class are less active and should be the focus of intervention efforts. A previous study showed that women with high prepregnancy BMI were less active than women with a low pregnancy BMI. ${ }^{30}$ By contrast, the present 


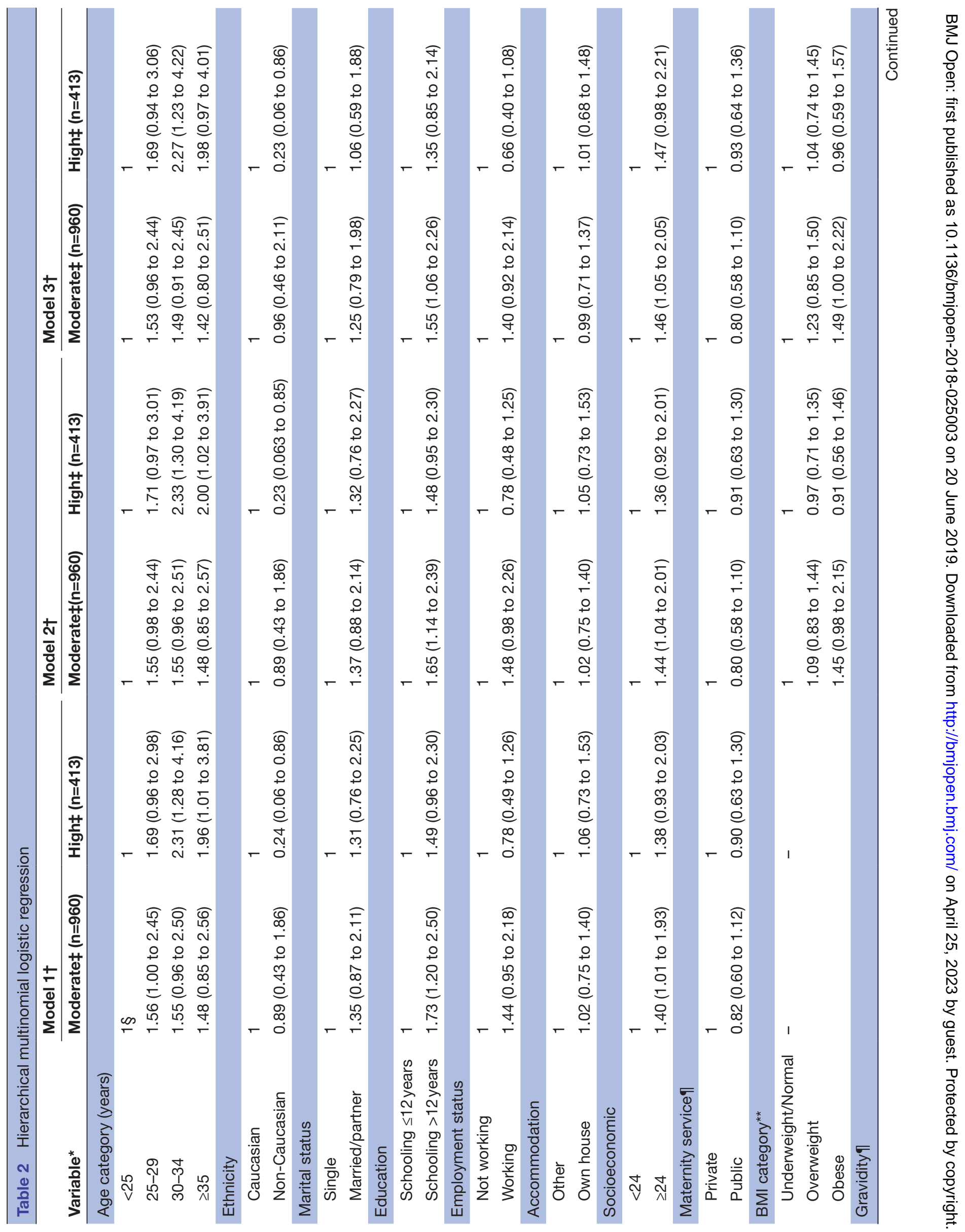




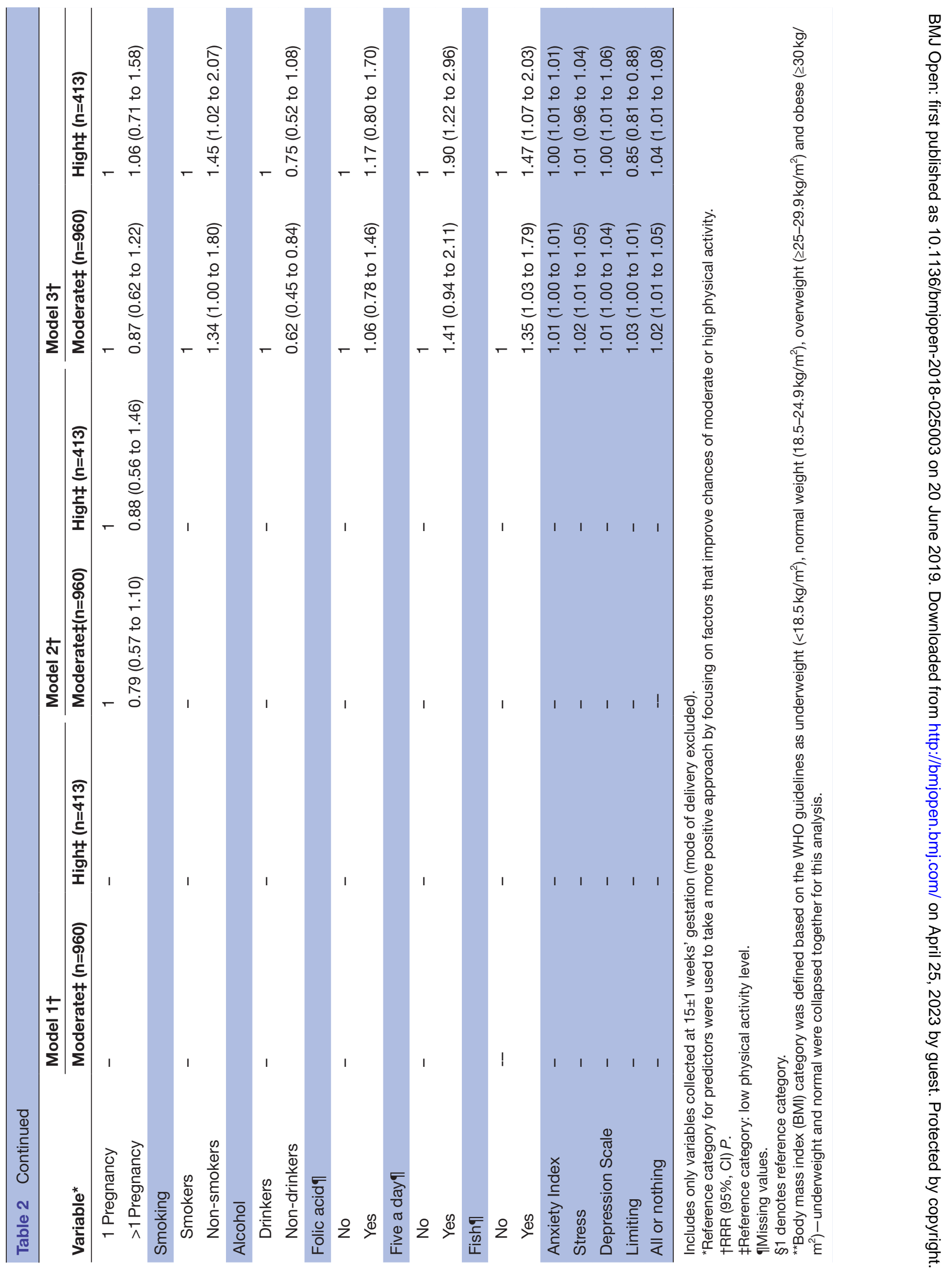


study showed that pregnant women in the obese BMI category $\left(\mathrm{BMI}>30 \mathrm{~kg} / \mathrm{m}^{2}\right.$ ) had increased probability of being in the moderate PA subgroup (vs the low). The relationship between BMI and PA observed in this and in other studies is complex. Obese women may be more likely to engage in less strenuous activity or these women may have over-reported their moderate PA levels due to the unclear descriptions of PA in the survey questions. Moreover, it could reflect perceived exertion where heavier women find themselves performing activity for which they feel like they are exerting themselves, relative to lighter women. Previous interventions for improving PA for pregnant women have focused on high-risk groups such as obese women. ${ }^{34}$ Non-smokers were more likely to be in the high PA subgroup relative to smokers, which is consistent with other studies. ${ }^{31} 35$ Furthermore, women who consumed the recommended five servings of fruit and vegetables per day and at least one serving of oily fish per week were more likely to be in the high PA subgroup, which indicates some awareness around healthy lifestyle behaviours during pregnancy. ${ }^{36}$ Dolan and Galizzi stated that no behaviour sits in a vacuum, and one healthy behaviour can greatly affect another. ${ }^{36}$ Furthermore, exercise and fruit and vegetable consumption have been identified as being in the same behavioural cluster ${ }^{37}$ and perhaps explain a potential spillover effect to PA as women are already engaging in a number of healthy behaviours. Women who drank alcohol during pregnancy were more likely to be in the moderate PA subgroup. This coexistence of healthy and unhealthy behaviours was also identified in other studies. ${ }^{38}$ Similar results were found in an Irish sample of adults aged 18 years and older, where the majority of moderate drinkers reported high levels of $\mathrm{PA} .{ }^{39}$

This analysis uses data from one of the largest studies of pregnant women (SCOPE). Furthermore, the population-based nature of the study allowed the estimation of the associations of a variety of social, biological, behavioural and psychological factors in a more representative sample than is often possible. Future research should find and use a better measure of PA to accurately assess PA levels and investigate the frequency, duration and intensity. While demographic correlates of PA are informative, they are largely unmodifiable. However, increased understanding of these correlates can be used to guide the development of interventions and to identify those who need the intervention, in this case, those with a low educational attainment and lower socioeconomic backgrounds.

\section{Limitations of this study}

This work is a secondary analysis of data collected with an observational study design. Inherent to the nature of the secondary analysis, the available data were not collected to address this particular research question. Furthermore, most of the data on maternal lifestyle factors were based on self-report and are susceptible to biased reporting of the lifestyle behaviours and physical activity. Lifestyle factors in the SCOPE study were based on a range of questions from a non-validated questionnaire, which should be acknowledged in order to interpret our results. Original survey questions on PA including vigorous exercise, moderate exercise and recreational walking used descriptions such as breathing and panting. Social desirability bias may have thus led to women over-reporting their PA levels. Although self-report has capacity to overestimate or underestimate true PA level, the use of daily exercise leading to heavy breathing or being out of breath has been used in other studies. ${ }^{40}$ A number of variables were re-categorised for the analysis, easy interpretation and presentation of results. ${ }^{41}$ However, by doing this, some information is lost, so caution must be used when interpreting the results as the statistical power to detect a relation between the variables and the PA outcome was reduced. Ethnicity needs to be interpreted with caution due to the low numbers of non-Caucasian women. However, the predominance of Caucasian women reflects the demographic profile of females aged 15-44 years in Ireland. ${ }^{42}$ In order to create a more robust indicator for this study, latent class analysis was conducted to classify pregnant women's PA subgroup based on multiple survey questions. The resulting classification should then be less prone to error than classifying participants based on any single question, but given that there is no gold standard to compare to, we must still rely on our subjective interpretation of the classification. Furthermore, the data from this study do not illustrate exercise conditions throughout pregnancy or the variation in exercise that may occur from trimester to trimester. Previous research advocates for the continuation of prepregnancy and early pregnancy PA levels into later pregnancy. ${ }^{43}$ Therefore, longitudinal follow-up is warranted in future studies.

\section{CONCLUSION}

This study identifies the links between social, biological, behavioural and psychological factors and PA level during pregnancy in a healthy pregnant population. The findings highlight some key potential links including those of a young maternal age, those with a low education level and those from a low socioeconomic background and PA. It also highlights potential behavioural clusters and spillover effects to PA. These factors should be considered for future interventions to improve PA levels during pregnancy.

\section{Author affiliations}

${ }^{1}$ School of Psychology, Health Behaviour Change Research Group, National University of Ireland Galway, Galway, Ireland

${ }^{2}$ School of Public Health, University College Cork, Cork, Ireland

${ }^{3}$ Health Research Board, Clinical Research Facility Cork, University College Cork, Cork, Ireland

${ }^{4}$ The Irish Centre for Fetal and Neonatal Translational Research (INFANT), University College Cork, Cork, Ireland

${ }^{5}$ Department of Women's and Children's Health, University of Liverpool School of Life Sciences, Liverpool, UK

${ }^{6}$ UCD Perinatal Research Centre, School of Medicine, University College Dublin, Dublin, Ireland

${ }^{7}$ National Maternity Hospital, University College Dublin, Dublin, Ireland

Contributors CF, AK, DD and SMMH formulated the overarching study aims and methodology. Data management was controlled by CF, who selected appropriate variables, cleaned and maintained the research data. DD conducted the latent 
class analysis and CF conducted the formal analysis, running the multinomial logistic regression. CF wrote the initial draft of the paper. MB, FMA, PMK and LCK contributed to successive drafts, reviewing and editing. All authors read and approved the final manuscript.

Funding This work was supported by Health Research Board Ireland (CSA/2007/2). LCK and AK are supported by a Science Foundation Ireland Program Grant for INFANT (12/RC/2272). CF is funded by the Health Research Board SPHeRE/2013/1.

Competing interests None declared.

Patient consent for publication Not required.

Ethics approval The SCOPE study was approved by the local ethics committee (Cork ECM5 (10) 05/02/08), all women provided written informed consent and the data were anonymised. For this study, research approval was obtained from the SCOPE team (RAF 3.66) and from the University College Cork, Office of Technology Transfer RU/2015/203.

Provenance and peer review Not commissioned; externally peer reviewed.

Data sharing statement All data generated or analysed during the current study are available from the SCOPE team on reasonable request.

Open access This is an open access article distributed in accordance with the Creative Commons Attribution Non Commercial (CC BY-NC 4.0) license, which permits others to distribute, remix, adapt, build upon this work non-commercially, and license their derivative works on different terms, provided the original work is properly cited, appropriate credit is given, any changes made indicated, and the use is non-commercial. See: http://creativecommons.org/licenses/by-nc/4.0/.

\section{REFERENCES}

1. World Health Organisation W. Physical Activity. Global Strategy on Diet, Physical Activity and Health. 2017 http://www.who.int/ dietphysicalactivity/pa/en/ (Accessed 4th Dec 2017).

2. The Royal College of Obstetricians and Gynecologists. Recreational exercise and pregnancy: information for you. 2006 https://wwwrcogorguk/globalassets/documents/patients/ patient-information-leaflets/pregnancy/recreational-exercise-andpregnancypdf.

3. Society of Obstetricians and Gynaecologists of Canada. Exercise in pregnancy and the postpartum periods. $2003 \mathrm{http}: / /$ sogcorg/wpcontent/uploads/2013/01/129E-JCPG-June2003pdf.

4. Smith $\mathrm{R}$, Reid $\mathrm{H}$, Matthews $\mathrm{A}$, et al. Infographic: physical activity for pregnant women. Br J Sports Med 2017.

5. American College of Obstetricians and Gynecologists. Exercise during pregnancy and the postpartum period. Clin Obstet Gynecol 2003;46:496-9.

6. Davies GA, Wolfe LA, Mottola MF, et al. Joint SOGC/CSEP clinical practice guideline: exercise in pregnancy and the postpartum period. Can J Appl Physiol 2003;28:329-41.

7. Melzer K, Schutz Y, Boulvain M, et al. Physical activity and pregnancy. Sports Medicine 2010;40:493-507.

8. Evenson KR, Wen F. National trends in self-reported physical activity and sedentary behaviors among pregnant women: NHANES 19992006. Prev Med 2010;50:123-8.

9. Walsh JM, McGowan C, Byrne J, et al. Prevalence of physical activity among healthy pregnant women in Ireland. Int J Gynaecol Obstet 2011;114:154-5.

10. Borodulin K, Evenson KR, Herring AH. Physical activity patterns during pregnancy through postpartum. BMC Womens Health 2009;9:1-7.

11. Evenson KR, Wen F. Prevalence and correlates of objectively measured physical activity and sedentary behavior among US pregnant women. Prev Med 2011;53(1-2):39-43.

12. Mottola MF, Campbell MK. Activity patterns during pregnancy. Can J Appl Physiol 2003;28:642-53.

13. Ning Y, Williams MA, Dempsey JC, et al. Correlates of recreational physical activity in early pregnancy. J Matern Fetal Neonatal Med 2003;13:385-93.

14. Gaston A, Cramp A. Exercise during pregnancy: a review of patterns and determinants. J Sci Med Sport 2011;14:299-305.

15. Liu J, Blair SN, Teng Y, et al. Physical activity during pregnancy in a prospective cohort of British women: results from the Avon longitudinal study of parents and children. Eur J Epidemiol 2011;26:237-47.

16. Gjestland K, Bø K, Owe KM, et al. Do pregnant women follow exercise guidelines? Prevalence data among 3482 women, and prediction of low-back pain, pelvic girdle pain and depression. $\mathrm{Br} \mathrm{J}$ Sports Med 2013;47:bjsports-2012-091344.

17. McCowan LM, Dekker GA, Chan E, et al. Spontaneous preterm birth and small for gestational age infants in women who stop smoking early in pregnancy: prospective cohort study. BMJ 2009;338:b1081.

18. North RA, McCowan LM, Dekker GA, et al. Clinical risk prediction for pre-eclampsia in nulliparous women: development of model in international prospective cohort. BMJ 2011;342:d1875.

19. McCowan L, North R, Taylor R. Australian New Zealand clinical trials registry. 2007.

20. Hagenaars JA, McCutcheon AL. Applied latent class analysis: Cambridge University Press. 2002.

21. Galbraith C, Jenkin G, Davis P, et al. New Zealand socio-economic index 1996. User's Guide Wellington: Statistics New Zealand. 2003

22. World Health Organization. Physical status: The use of and interpretation of anthropometry, Report of a WHO Expert Committee. 1995.

23. Marteau TM, Bekker H. The development of a six-item short-form of the state scale of the Spielberger State-Trait Anxiety Inventory (STAI). Br J Clin Psychol 1992;31:301-6.

24. Cohen S, Kamarck T, Mermelstein R. A global measure of perceived stress. J Health Soc Behav 1983;24:385-96.

25. Peindl KS, Wisner KL, Hanusa BH. Identifying depression in the first postpartum year: guidelines for office-based screening and referral. $J$ Affect Disord 2004;80:37-44.

26. Spence M, Moss-Morris R, Chalder T. The Behavioural Responses to Illness Questionnaire (BRIQ): a new predictive measure of medically unexplained symptoms following acute infection. Psychol Med 2005;35:583-93.

27. McCarthy FP, Moss-Morris R, Khashan AS, et al. Previous pregnancy loss has an adverse impact on distress and behaviour in subsequent pregnancy. BJOG 2015;122:1757-64

28. Engel GL. The clinical application of the biopsychosocial model. J Med Philos 1981;6:101-24.

29. Victora CG, Huttly SR, Fuchs SC, et al. The role of conceptual frameworks in epidemiological analysis: a hierarchical approach. Int J Epidemiol 1997;26:224-7.

30. Foxcroft KF, Rowlands IJ, Byrne NM, et al. Exercise in obese pregnant women: the role of social factors, lifestyle and pregnancy symptoms. BMC Pregnancy Childbirth 2011;11:4.

31. Chasan-Taber L, Schmidt MD, Pekow P, et al. Correlates of physical activity in pregnancy among Latina women. Matern Child Health $\mathrm{J}$ 2007;11:353-63.

32. Schmidt MD, Pekow P, Freedson PS, et al. Physical activity patterns during pregnancy in a diverse population of women. $J$ Womens Health 2006;15:909-18.

33. Giles-Corti B, Donovan RJ. Socioeconomic status differences in recreational physical activity levels and real and perceived access to a supportive physical environment. Prev Med 2002;35:601-11.

34. Pearce EE, Evenson KR, Downs DS, et al. Strategies to Promote Physical Activity During Pregnancy. Am J Lifestyle Med 2013;7:38-50.

35. Petersen AM, Leet TL, Brownson RC. Correlates of physical activity among pregnant women in the United States. Med Sci Sports Exerc 2005;37:1748-53.

36. Dolan P, Galizzi MM. Like ripples on a pond: Behavioral spillovers and their implications for research and policy. J Econ Psychol 2015;47:1-16.

37. Nudelman G, Shiloh S. Mapping health behaviors: Constructing and validating a common-sense taxonomy of health behaviors. Soc Sci Med 2015;146:1-10.

38. Poortinga W. The prevalence and clustering of four major lifestyle risk factors in an English adult population. Prev Med 2007;44:124-8 https://doi.org/.

39. Conry MC, Morgan K, Curry P, et al. The clustering of health behaviours in Ireland and their relationship with mental health, selfrated health and quality of life. BMC Public Health 2011;11:692.

40. Bell RJ, Palma SM, Lumley JM. The effect of vigorous exercise during pregnancy on birth-weight. Aust N Z J Obstet Gynaecol 1995;35:46-51.

41. Altman DG, Royston P. The cost of dichotomising continuous variables. BMJ 2006;332:1080.1-80.

42. Office ICS.. Census Volume 5- Ethnic or Cultural Background 2006 https://www.cso.ie/en/csolatestnews/pressreleases/ 2007pressreleases/2006censusofpopulation-volume5ethnicorcultu ralbackgroundincludingtheirishtravellercommunity/.

43. Norris T, McCarthy FP, Khashan AS, et al. Do changing levels of maternal exercise during pregnancy affect neonatal adiposity? Secondary analysis of the babies after SCOPE: evaluating the longitudinal impact using neurological and nutritional endpoints (BASELINE) birth cohort (Cork, Ireland). BMJ Open 2017;7:e017987. 